\title{
Characteristic Analysis of Concrete for Radiation Shielding Evaluation of Gamma Irradiation Facilities
}

\author{
Ki-tek Han ${ }^{1}$, Sang Mook Kang ${ }^{1}$, Jeho Min ${ }^{1}$ and Han Ki Jang ${ }^{1, a}$ \\ ${ }^{1}$ KARA, Quality Assurance Center for Medical Radiation, 0479077 Seongsuil-ro Seongdong-gu Seoul, Korea
}

\begin{abstract}
Physical and chemical properties of concrete sample was obtained using various methods such as density analysis, elemental analysis and WD-XRF analysis to get accurate characteristics of concrete collected in our construction site in Korea. Using these results, in this study, we perform the simulation to compare the dose evaluation results between NBS concrete of ANSI/ANS 6.4.3 and characteristics of concrete samples using MCNPX. As a result, simulation results of collected concrete samples in our facility were underestimated up to $54.01 \%$. Through these results, we verify the necessity of accurate properties of materials.
\end{abstract}

\section{Introduction}

Monte Carlo radiation transport computer codes such as MCNPX, Geant4 are widely used in radiation shielding evaluation(RSE)[1].

Most case of concrete in RSE with Monte Carlo radiation transport computer code, National Bureau of Standards(NBS) concrete values in ANSI/ANS 6.4.3 is widely used[2-3]. However, there are many differences between NBS concrete properties in ANSI/ANS 6.4.3 and real concrete. So that reason, RSE results may overestimate or underestimate. To improve this problem, exact characteristics of material such as density and weight fraction is necessary.

There are many advantages to using real properties of materials. For example, it helps prevent overestimate or underestimate, thereby calculating accurate construction cost.

In this study, we collected concrete samples from our construction site of gamma irradiation rooms in Quality Assurance Center for Medical Radiation of the Korean Association for Radiation Application(KARA). Using these concrete samples, we carried out physical and chemical analysis such as density analysis, elemental analysis(EA) and X-ray fluorescence(XRF) analysis to get accurate properties for characteristics of concrete.

Finally, we perform the simulation using MCNPX Monte Carlo radiation transport computer code to compare the gamma-ray shielding performance between NBS concrete and concrete samples collected in our construction site.

\section{Materials and Methods}

\subsection{Preparation of Concrete Samples}

For analyzing characteristics of real concretes, we prepare concrete samples as shown in figure 1. These concrete samples are collected from various part of gamma irradiation rooms in Quality Assurance Center for Medical Radiation. And collected concrete samples were made by two types, cylinder and rectangular type.

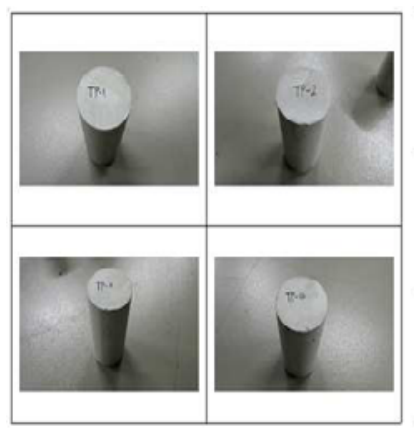

(a)

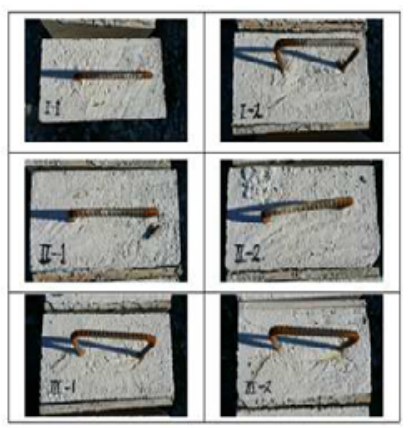

(b)
Figure 1. Concrete samples(a: cylinder type, b: rectangular type).

\subsection{Characteristics Analysis}

As mentioned, we carried out concrete sample analysis to obtain physical and chemical properties. Concrete samples were analyzed in three ways, density analysis, elemental analysis(EA) and wavelength dispersive X-ray fluorescence (WD-XRF) analysis using five cylinder type samples.

\footnotetext{
${ }^{\mathrm{a}}$ Corresponding author: hkjang@ri.or.kr
} 


\subsubsection{Density Analysis}

Density of collected concrete samples were measured by Korea Conformity Laboratory (KCL) following KS F 2459:2002[4].

\subsubsection{Elemental Analysis}

Generally, EA method is used in quantitative analysis for organic properties such as hydrogen, carbon, oxygen, nitrogen and sulfur. This test was measured by Korea Basic Science Institute (KBSI). using elemental analyzer.

\subsubsection{WD-XRF Analysis}

$\mathrm{XRF}$ analysis using WD-XRF is widely used in quantitative analysis of inorganic properties of material. For analyzing samples using WD-XRF, pretreatment is necessary as shown in figure 2 .

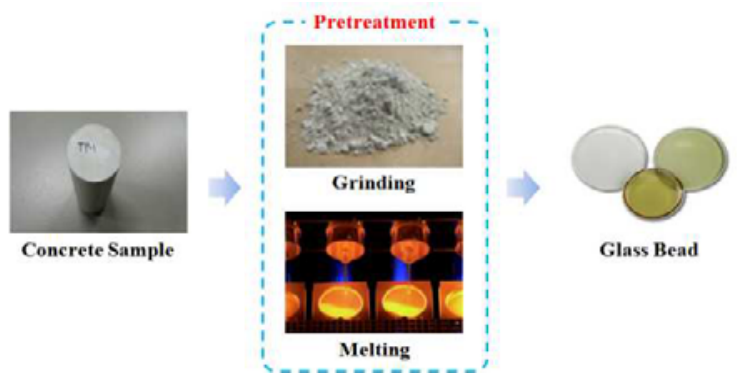

Figure 2. Pretreatment process of sample.

\section{Experimental Results}

\subsection{Results of Characteristics Analysis}

In this study, we analyze characteristics of concrete samples to obtain physical and chemical properties.

Table 1 shows the results of density analysis. Average density of $2.208 \mathrm{~g} / \mathrm{cm}^{3}$ and a relative standard deviation(RSD \%) of 1.044 was obtained.

Table 1. Measurement of .concrete density.

\begin{tabular}{|c|c|c|c|c|c|}
\hline \multirow{2}{*}{ Samples } & \multicolumn{5}{|c|}{ Concrete Samples (Test Piece, TP) } \\
\cline { 2 - 6 } & TP-1 & TP-3 & TP-2 & TP-4 & TP-5 \\
\hline $\begin{array}{c}\text { Density } \\
\text { (g/cm }\end{array}$ & 2.199 & 2.217 & 2.179 & 2.202 & 2.241 \\
\hline \multicolumn{3}{|c|}{ Average } & \multicolumn{4}{|c|}{$2.208 \mathrm{~g} / \mathrm{cm}^{3}$} \\
\hline
\end{tabular}

In case of EA, properties of carbon, hydrogen and oxygen were obtained as shown in table 2. And the WDXRF results obtained from five collected concrete samples in oxide form were shown in table 3.

Table 2. Elemental analysis results.

\begin{tabular}{|c|c|c|c|c|c|}
\hline Element & $\mathbf{C}$ & $\mathbf{H}$ & $\mathbf{O}$ & $\mathbf{N}$ & $\mathbf{S}$ \\
\hline $\begin{array}{c}\text { Weight } \\
\text { Fraction } \\
\text { (wt \%) }\end{array}$ & $\begin{array}{c}1.07 \\
\pm 0.01\end{array}$ & $\begin{array}{c}0.05 \\
\pm 0.01\end{array}$ & $\begin{array}{c}6.09 \\
\pm 0.05\end{array}$ & None & None \\
\hline
\end{tabular}

Table 3. WD-XRF analysis Results.

\begin{tabular}{|c|c|}
\hline Oxygen Compounds & Weight Fraction (wt \%) \\
\hline $\mathrm{Al}_{2} \mathrm{O}_{3}$ & $12.49 \pm 0.32$ \\
\hline $\mathrm{CaO}$ & $11.53 \pm 0.40$ \\
\hline $\mathrm{Fe}_{2} \mathrm{O}_{3}$ & $2.13 \pm 0.42$ \\
\hline $\mathrm{K}_{2} \mathrm{O}$ & $3.00 \pm 0.19$ \\
\hline $\mathrm{MgO}$ & $1.39 \pm 0.39$ \\
\hline $\mathrm{MnO}$ & $0.08 \pm 0.05$ \\
\hline $\mathrm{Na}_{2} \mathrm{O}$ & $3.05 \pm 0.23$ \\
\hline $\mathrm{P}_{2} \mathrm{O}_{5}$ & $0.13 \pm 0.10$ \\
\hline $\mathrm{SiO}_{2}$ & $58.77 \pm 0.70$ \\
\hline $\mathrm{TiO}_{2}$ & $0.34 \pm 0.17$ \\
\hline $\mathrm{L} . \mathrm{O} . \mathrm{I}$ & $6.29 \pm 0.36$ \\
\hline $\mathrm{Total}$ & $99.20 \pm 0.28$ \\
\hline
\end{tabular}

Table 4 shows comparison of ANSI/ANS 6.4.3 and experimental results. Experimental results were obtained from calculation of EA and WD-XRF results. As a result, element properties are similar. However some elements are little different such as carbon, phosphorus, sulfur and titanium.

Table 4. Comparison of ANSI/ANS 6.4.3 and experimental results.

\begin{tabular}{|c|c|c|}
\hline \multirow{2}{*}{ Elements } & \multicolumn{2}{|c|}{ Weight Fraction } \\
\cline { 2 - 3 } & ANSI 6.4.3 & This Study \\
\hline Hydrogen & 0.006 & 0.005 \\
\hline Carbon & - & 0.011 \\
\hline Oxygen & 0.498 & 0.493 \\
\hline Sodium & 0.017 & 0.020 \\
\hline Magnesium & 0.002 & 0.016 \\
\hline Aluminum & 0.046 & 0.060 \\
\hline Silicon & 0.316 & 0.258 \\
\hline Phosphorus & - & 0.001 \\
\hline Sulfur & 0.001 & - \\
\hline Potassium & 0.019 & 0.025 \\
\hline Calcium & 0.083 & 0.084 \\
\hline Iron & 0.012 & 0.024 \\
\hline Titanium & - & 0.003 \\
\hline Total & 1 & 1 \\
\hline
\end{tabular}

\subsection{Comparison of Shielding Performance}

To compare gamma-ray shielding performance between ANSI/ANS 6.4.3 NBS concrete and concrete sample collected in our construction site, we perform the simulation through the MCNPX Monte Carlo radiation transport computer code work.

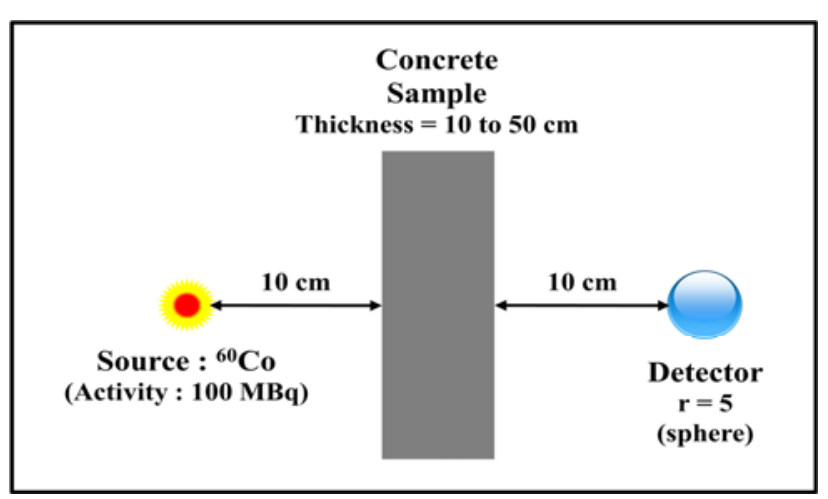

Figure 3. Geometry of MCNPX simulation 
Figure 3 shows geometry of MCNPX simulation. RSE performed according to thickness of concrete samples using $100 \mathrm{MBq}{ }^{60} \mathrm{Co}$ radiation source. The thickness of concrete increases by $5 \mathrm{~cm}$ increments from 10 to $50 \mathrm{~cm}$. In case of radiation detector, sphere type with a radius of $5 \mathrm{~cm}$ was used.

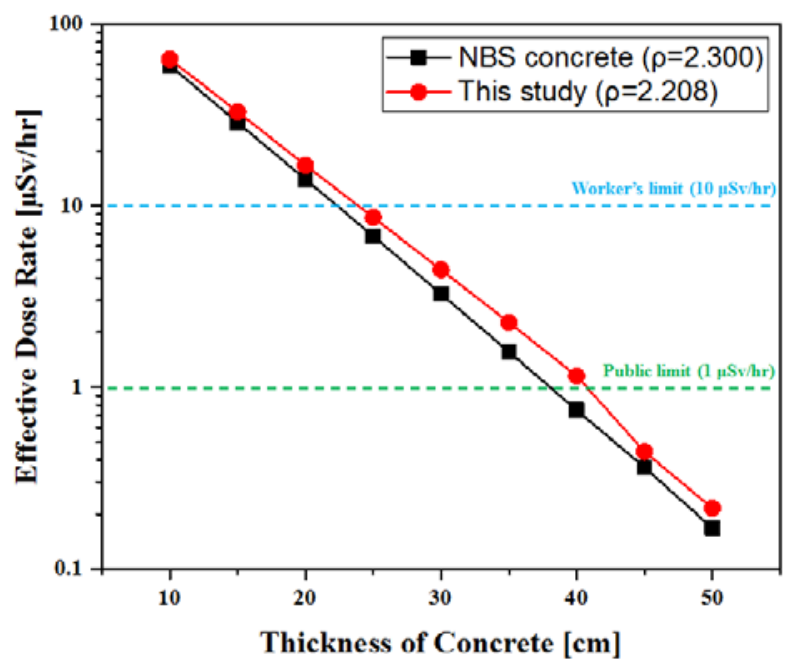

Figure 4. MCNPX simulation results according to thickness of concrete samples.

Figure 4 shows MCNPX simulation results, according to thickness of concrete samples. These results are calculated by tally 4 in MCNPX and ICRP 74 DCF(dose conversion factor) was used to convert effective dose per photon fluence. Relative errors of all calculated results are less than $1 \%$. As a result, simulation results of collected concrete samples in our facility were underestimated up to $54.01 \%$ against NBS concrete. Therefore, accurate properties of material is necessary to prevent overestimate or underestimate.

\section{Conclusion}

In this study, we obtained physical and chemical properties of concrete samples collected from our construction site. Using this properties, shielding performance compared between NBS concrete and collected concrete sample using MCNPX. In conclusion, we verify that accurate properties of material are necessary to prevent overestimate or underestimate in RSE.

Further studies will be carried out experiments using collected concrete samples and various gamma irradiation systems such as ${ }^{60} \mathrm{Co},{ }^{137} \mathrm{Cs}$, and ${ }^{192} \mathrm{Ir}$ irradiation systems.

\section{References}

1. A.M. El-khayatt, Ann Nucl Energy 38, 128 (2011)

2. Oak Ridge National Laboratory, ORNL/RSIC-49 (1988)

3. K.S. Mann, T. Korkut, Ann Nucl Energy 41, 81 (2013)
4. Korea Agency for Technology and Standards, KS F 2459 (2002). 